\title{
Assembly and Turnover of Caveolae: What Do We Really Know?
}

\author{
Bing Han ${ }^{1}$, Courtney A. Copeland ${ }^{1}$, Ajit Tiwari ${ }^{1}$ and Anne K. Kenworthy ${ }^{1,2,3,4 *}$ \\ ${ }^{1}$ Department of Molecular Physiology and Biophysics, Vanderbilt University School of Medicine, Nashville, TN, USA, \\ ${ }^{2}$ Department of Cell and Developmental Biology, Vanderbilt University School of Medicine, Nashville, TN, USA, ${ }^{3}$ Epithelial \\ Biology Program, Vanderbilt University School of Medicine, Nashville, TN, USA, ${ }^{4}$ Chemical and Physical Biology Program, \\ Vanderbilt University, Nashville, TN, USA
}

\section{OPEN ACCESS}

Edited by:

David Holowka,

Cornell University, USA

Reviewed by:

Irena Levitan,

University of Illinois at Chicago, USA

Enrique Hernandez-Lemus,

National Institute of Genomic

Medicine, Mexico

Christophe Lamaze,

Institut Curie, France

*Correspondence:

Anne K. Kenworthy

anne.kenworthy@vanderbilt.edu

Specialty section:

This article was submitted to

Membrane Physiology and Membrane

Biophysics,

a section of the journal

Frontiers in Cell and Developmental

Biology

Received: 27 April 2016

Accepted: 13 June 2016

Published: 27 June 2016

Citation:

Han B, Copeland CA, Tiwari A and Kenworthy AK (2016) Assembly and

Turnover of Caveolae: What Do We Really Know?

Front. Cell Dev. Biol. 4:68.

doi: 10.3389/fcell.2016.00068
In addition to containing highly dynamic nanoscale domains, the plasma membranes of many cell types are decorated with caveolae, flask-shaped domains enriched in the structural protein caveolin-1 (Cav1). The importance of caveolae in numerous cellular functions and processes has become well-recognized, and recent years have seen dramatic advances in our understanding of how caveolae assemble and the mechanisms control the turnover of Cav1. At the same time, work from our lab and others have revealed that commonly utilized strategies such as overexpression and tagging of Cav1 have unexpectedly complex consequences on the trafficking and fate of Cav1. Here, we discuss the implications of these findings for current models of caveolae biogenesis and Cav1 turnover. In addition, we discuss how disease-associated mutants of Cav1 impact caveolae assembly and outline open questions in this still-emerging area.

Keywords: caveolae, caveolin-1, GFP, trafficking, degradation, breast cancer, pulmonary arterial hypertension, congenital generalized lipodystrophy

\section{INTRODUCTION}

In addition to containing nanoclusters of proteins and lipids, the surface of many cell types also contain relatively stable flask-shaped invaginations that are 50-100 $\mathrm{nm}$ in diameter known as caveolae. Initially discovered nearly 60 years ago in the plasma membranes of endothelial cells of blood capillaries by electron microscopy, caveolae have been a target of scientific investigation for decades (Palade, 1953). The discovery of the first caveolae-associated protein caveolin-1 (Cav1) almost 40 years after the discovery of caveolae has greatly facilitated research into the structural and functional aspects of caveolae (Kurzchalia et al., 1992; Rothberg et al., 1992). To date, caveolae have been identified in a variety of tissues and cell types including endothelial cells, smooth muscle cells, fibroblasts, myoblasts, and adipocytes, among others (Hansen et al., 2013; Parton and del Pozo, 2013), and the importance of a series of accessory proteins in sculpting caveolae and regulating their dynamics is also now recognized (Hill et al., 2008; Hansen and Nichols, 2010; Hansen et al., 2011; Moren et al., 2012; Stoeber et al., 2012; Ariotti and Parton, 2013; Ludwig et al., 2013; Kovtun et al., 2014, 2015). It is also now clear that once formed, caveolae can flatten in response to membrane stretch and thus serve as membrane reservoirs (Gervasio et al., 2011; Sinha et al., 2011).

Unlike the more controversial case of lipid rafts (Owen et al., 2012; Kraft, 2013; LaRocca et al., 2013; Sevcsik and Schutz, 2016), caveolae are relatively stable structures and also thus readily detectable by conventional fluorescence and electron microscopy approaches. In addition, their presence in cells absolutely depends on the expression of Cav1, making them amenable to a range of biochemical and biophysical analyses as well as studies in animal models (Drab et al., 2001; Razani et al., 2001; Le Lay and Kurzchalia, 2005). Through these varied approaches, the importance of 
caveolae in numerous cellular functions and processes has become well-recognized, and are thought to include roles in signal transduction, endocytosis, pathogen invasion, lipid homeostasis, and mechanotransduction (Parton and Simons, 2007; Hansen and Nichols, 2010; Ariotti and Parton, 2013; Parton and del Pozo, 2013; Cheng and Nichols, 2016). Furthermore, Cav1 and other caveolins have been implicated several pulmonary and vascular diseases, myopathies, lipodystrophies, and cancers (Hayashi et al., 2001; Razani and Lisanti, 2001; Cao et al., 2008; Kim et al., 2008; Mercier et al., 2009; Austin et al., 2012; Ariotti and Parton, 2013; Garg et al., 2015; Martinez-Outschoorn et al., 2015).

Given the importance of caveolae in both health and disease, it is critical to gain a clear understanding of how caveolae form and the mechanisms responsible for the turnover of their components. In this mini-review, we summarize current knowledge in these areas, including the unexpectedly complex consequences that overexpression and tagging of Cav1 can have on the trafficking and fate of Cavl and caveolae biogenesis. In addition, we discuss how disease-associated mutants of Cav1 impact caveolae assembly and turnover and outline open questions in this emerging area.

\section{WHAT CONDITIONS ARE NECESSARY FOR CAVEOLAE TO FORM CORRECTLY?}

It is widely accepted that the assembly of caveolae requires the expression of Cav1 (Drab et al., 2001; Razani et al., 2001). A 178 amino acid-long protein, Cav1 is anchored to the membrane by an intra-membrane region that assumes a hairpinlike topology. The Cav1 protein contains four domains: the $\mathrm{N}$-terminal domain (residues 1-81), scaffolding domain (CSD, residues 82-101), transmembrane domain (TMD, residues 102134), and C-terminal domain (residues 135-178) (Root et al., 2015). The transmembrane domain is composed of two $\alpha$-helices separated by three residue linker region containing a proline (P110) that induces a $\sim 50^{\circ}$ angle between the two $\alpha$-helices (Root et al., 2015). This allows Cav1 to adopt a hairpin topology in the lipid bilayer such that both $\mathrm{N}$ - and $\mathrm{C}$ - termini are exposed to the cytoplasmic interior of the cell (Root et al., 2015). To date, however, the three dimensional structure of Cav1 remains unknown.

Cav1 is synthesized in the endoplasmic reticulum and undergoes a complicated series of oligomerization and trafficking events well before reaching the plasma membrane (Figure 1). Newly synthesized Cav1 is quickly organized into Cav1/Cav2 (caveolin-2) hetero-oligomers that contains 14-16 monomers (Monier et al., 1995; Sargiacomo et al., 1995) and partition as an 8 S complex on sucrose gradients (Hayer et al., 2010a). This 8S-oligomerization step appears to be pivotal for the proper assembly of caveolae, because forms of Cav1 that fail to oligomerize are unable to independently assemble into caveolae (Mora et al., 1999; Lee et al., 2002; Ren et al., 2004; Shatz et al., 2010). Thereafter, 8 S complexes are transported to the Golgi complex in a COPII-dependent mechanism where they serve as the subunits necessary for the assembly of filament-like $70 \mathrm{~S}$ complexes that become enriched in cholesterol and lose their diffusional mobility. The cholesterol-rich membranes containing 70S Cav1 complexes are then transported to the cell surface (Hayer et al., 2010a).

At the plasma membrane, several accessory proteins are subsequently recruited to caveolin complexes to facilitate caveolae formation and assist in sculpting caveolar membranes as well as regulate caveolae dynamics. They include members of the cavin gene family, pacsin-2, and EHD-2 (Aboulaich et al., 2004; Hill et al., 2008; Hansen and Nichols, 2010; Hansen et al., 2011; Moren et al., 2012; Stoeber et al., 2012; Ariotti and Parton, 2013; Ludwig et al., 2013; Kovtun et al., 2014, 2015). Cavin-1 plays an important role in forming caveolae, as cavin-1 knockdown significantly reduces caveolae number in both mammalian cells and zebrafish (Hill et al., 2008) and cavin-1 knockout mice lack caveolae altogether (Liu et al., 2008). Additional cavin family members have also been identified, and recent studies have elucidated the organization and structure of multiple cavincontaining complexes (Hayer et al., 2010a; Ludwig et al., 2013; Gambin et al., 2014; Kovtun et al., 2014, 2015). These findings have been reviewed in detail elsewhere (Kovtun et al., 2015) and will not be discussed further here. EHD-2 is thought to help confine caveolae and reduce mobility at the plasma membrane through interactions with actin (Moren et al., 2012; Stoeber et al., 2012). Pacsin-2, which contains a membrane curvatureassociated F-BAR domain, has also been reported to be recruited to and assist in sculpting caveolae (Hansen et al., 2011; Senju et al., 2011). Furthermore, post-translational modifications of Cav1 such as palmitoylation and phosphorylation also regulate steps in caveolae assembly and caveolae structure (Monier et al., 1996; Nomura and Fujimoto, 1999; Zimnicka et al., 2016). However, expression of Cav1 in a bacterial expression system can drive the formation of heterologous caveolae. Thus, Cav1 itself is capable of inducing membrane curvature in some membrane environments, even without the help of accessory proteins (Walser et al., 2012; Ariotti et al., 2015).

The use of fluorescent protein-tagged forms of Cav1 has made it possible to assess caveolae biogenesis and dynamics. Such experiments have often been carried out by expressing low levels of Cav1 in $\mathrm{Cav1}^{-/-}$mouse embryonic fibroblasts (Kirkham et al., 2008; Ariotti et al., 2015) or more recently at endogenous expression levels in genome-edited cell lines (Shvets et al., 2015). However, a large literature also exists where Cav1 has been studied in the context of overexpression systems. One potential caveat of such studies is that both overexpression and tagging strategies can interfere with caveolae biogenesis (Parton and del Pozo, 2013). For example, it has been reported that in some cell types, after a few hours of expression overexpressed Cav1 fails to co-localize with endogenous Cav1, implying that exogenous Cav1 is not always incorporated into caveolae (Hayer et al., 2010b). Indeed, caveolin-enriched organelles termed "caveosomes" were later shown to arise as a consequence of the accumulation of overexpressed caveolin in late endosomal structures (Pelkmans et al., 2001; Hayer et al., 2010b).

Studies from our own group further have revealed that the behavior of overexpressed Cav1 also depends on the type of the tag (Hanson et al., 2013; Han et al., 2015). In 


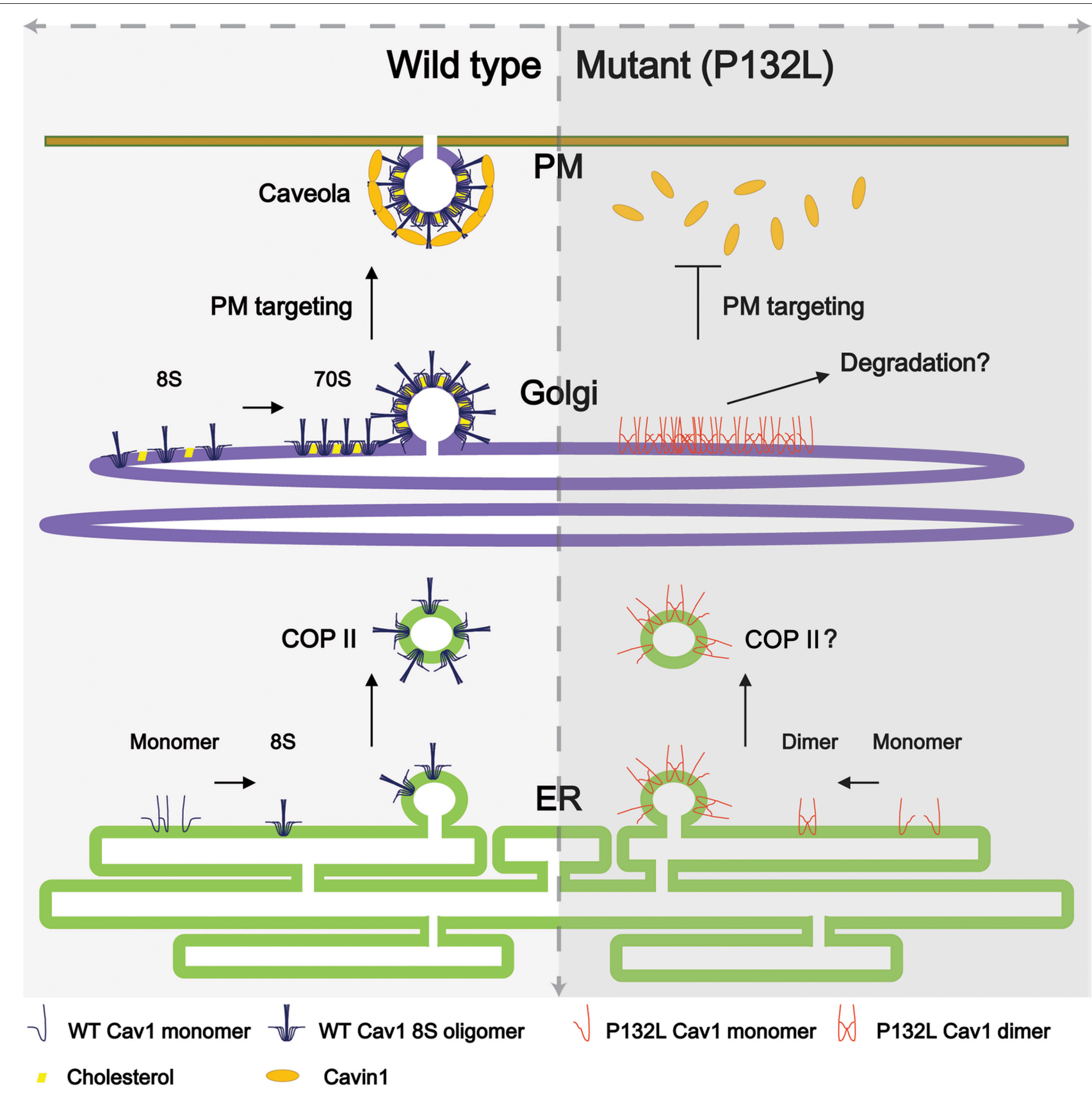

FIGURE 1 | Current model of caveolae biogenesis. (Left) Newly synthesized wild type Cav1 undergoes a series of oligomerization events as it passes through the secretory pathway. At the plasma membrane, accessory proteins interact with Cav1 complexes to form mature caveolae. (Right) In contrast, a breast-cancer associated mutant of Cav1, Cav1-P132L, is unable to oligomerize correctly and accumulates in the Golgi complex, where it is likely targeted for degradation. For simplicity, not all caveolae accessory proteins are illustrated here.

COS-7 cells, for example, Cav1-GFP strongly accumulates in a perinuclear compartment (Hanson et al., 2013) in the form of irregular aggregates that contain little if any endogenous Cav1 (Han et al., 2015). The behavior of Cav1-mCherry differs dramatically from that of Cav1-GFP in the same cell line, both in terms of its subcellular localization (Hanson et al., 2013) and biochemical properties (Han et al., 2015). Furthermore, the degree to which Cav1-GFP accumulates intracellularly depends on the cell type in which it is expressed (Hanson et al., 2013). Thus, the ability of Cav1 to form oligomers and traffic correctly to the plasma membrane is heavily dependent on how the protein is tagged as well as the cellular environment, pointing to the exquisitely sensitive nature of caveolae assembly. 


\section{WHAT MECHANISMS ARE RESPONSIBLE FOR THE TURNOVER OF CAV1 AND CAVEOLAE?}

Cav1 is known to be a relatively long-lived protein; estimates of the half-life of endogenous Cav1 from metabolic labeling studies range from 5 to $36 \mathrm{~h}$ (Conrad et al., 1995; Forbes et al., 2007; Hayer et al., 2010b). Turnover of Cav1 is accelerated under conditions that compromise caveolar assembly and/or destabilize 70 S caveolar scaffolds (Hayer et al., 2010b). Under these conditions, Cav1 is ubiquitinated and targeted to endosomal sorting complex required for transport (ESCRT) machinery via intraluminal vesicles of multi-vesicular bodies and subsequently is degraded within lysosomes (Hayer et al., 2010b). Thus, under these conditions Cav1 behaves as endocytic cargo that is targeted to early endosomes and follows a classical endocytic pathway leading to degradation.

More recent evidence has revealed additional cellular machinery involved in Cav1 turnover by this pathway. One major contributor is Valosin Containing Protein (VCP/p97), an AAA-ATPase that functions in processing of ubiquitinated cellular proteins. Along with its cofactor UBXD1, VCP binds to monoubiquitinated Cavl on endosomes and in turn influences trafficking, endosomal sorting, and degradation of Cav1 (Ritz et al., 2011). The ubiquitination events required for targeting Cav1 into this pathway occur at the N-terminal region of the protein (Kirchner et al., 2013). Turnover of ubiquitinated Cav1 is aided by the Ankrd13 proteins, which contain a ubiquitin interacting motif that bind to polyubiquinated Cav1 oligomers on endosomes (Burana et al., 2016). While these studies have defined a distinct pathway that controls the turnover of Cavl, there are hints in the literature that additional machinery and mechanisms involved in Cav1 turnover remain to be discovered (Austin et al., 2012; Bakhshi et al., 2013; Cha et al., 2015; Mougeolle et al., 2015; Schrauwen et al., 2015).

\section{HOW DO DISEASE-ASSOCIATED MUTATIONS AFFECT CAVEOLAE ASSEMBLY AND TURNOVER?}

Cav1 has been implicated as a key player in a number of human diseases, and several disease-associated mutations in Cav1 have been identified (Hayashi et al., 2001; Razani and Lisanti, 2001; Cohen et al., 2004; Cao et al., 2008; Kim et al., 2008; Mercier et al., 2009; Austin et al., 2012; Ariotti and Parton, 2013; Garg et al., 2015; Martinez-Outschoorn et al., 2015). Perhaps the best known example is Cav1-P132L, originally identified as a somatic mutation associated with breast cancer (Hayashi et al., 2001). Although, the frequency with which this mutation occurs in humans has been highly debated (Hayashi et al., 2001; Lee et al., 2002; Koike et al., 2010; Lacroix-Triki et al., 2010; Ferraldeschi et al., 2012; Patani et al., 2012), Cav1-P132L has become a useful model for studying the behavior of mistrafficked forms of Cav1. This is because unlike wild type Cav1, Cav1-P132L typically localizes to the perinuclear region in a compartment proposed to correspond to the Golgi complex and does not form caveolae
(Lee et al., 2002). Furthermore, Cav1-P132L primarily exists as monomer or dimer instead of the typical oligomers of wild type Cav1 observed in the cell (Lee et al., 2002; Ren et al., 2004; Hayer et al., 2010a; Rieth et al., 2012; Han et al., 2015). These features of Cav1-P132L differ substantially from the behavior of wild type Cav1 (Figure 1).

Interestingly, Cav1-P132L can also impact the behavior of wild type Cav1. In one of the earliest studies of Cav1-P132L, co-expression of Cav1-P132L with wild type Cav1 was shown to lead to a loss of wild type Cavl's affinity for detergent resistant membranes as well as to trap wild type Cav1 together with Cav1P132L in a perinuclear compartment. Based on these findings, it was concluded that Cav1-P132L behaves in a dominant-negative manner, thereby interfering with caveolae formation (Lee et al., 2002). However, another study found that when co-expressed with wild type Cav1, Cav1-P132L had no effect on the localization of wild type Cav1 in FRT cells even though the mutant protein was localized in a perinuclear compartment (Ren et al., 2004). A different group showed that the number of caveolae increased upon stable expression of Cav1-P132L in H1299 cells, a cell line derived from human non-small cell carcinoma that endogenously expresses wild type Cav1 (Shatz et al., 2010). Thus, conflicting evidence exists as to how Cav1-P132L impacts caveolae assembly and function.

Why these behaviors of Cav1-P132L differ so much across studies is not yet clear. One potential clue comes from our recent observation that simply overexpressing Cav1-GFP causes a large fraction of the protein to be targeted to a perinuclear structure in COS-7 cells (Hanson et al., 2013). Furthermore, forms of Cav1 that were targeted to the plasma membrane when expressed separately became trapped intracellularly when they were co-expressed with Cav1-GFP (Hanson et al., 2013). Thus, in this system Cav1-GFP mimics the dominant negative trafficking defect originally reported for the Cav1-P123L mutant (Lee et al., 2002). Further, we observed that the majority of Cav1GFP was degraded within $5 \mathrm{~h}$, suggesting it may be improperly folded and thus targeted for degradation (Hanson et al., 2013). These findings raise the possibility that the dominant negative behavior reported for Cav1-P132L might at least in part be the result of misfolding induced by a combination of tagging and overexpression. They also raise questions about the identity of the perinuclear compartment that Cav1-GFP and Cav1-P132L accumulate in. In the case of Cav1-P132L, this compartment was originally proposed to correspond to the Golgi complex (Lee et al., 2002). However, given that perinuclear Cav1-GFP forms irregular aggregates, another possibility is that Cavl-GFP associates with aggresomes, structures that form in response to the accumulation of protein aggregates too large to be degraded by the proteasome (Wojcik et al., 1996; Johnston et al., 1998; Kopito, 2000; Garcia-Mata et al., 2002; Hyttinen et al., 2014). If this is the case, it would have important consequences for our current understanding of trafficking defects ascribed to mutant forms of both Cav1 and other caveolin family members, including a dominant negative P104L mutation in caveolin3 associated with muscular dystrophy that corresponds to the P132L mutation in Cav1 (Carozzi et al., 2002; Sotgia et al., 2003; Pol et al., 2005; Cai et al., 2009). 
In addition to Cav1-P132L, in recent years several additional disease-associated mutants of Cav1 have been identified, including one homozygous null mutation and three heterozygous frameshift mutations in the Cav1 gene identified in patients with pulmonary arterial hypertension (PAH), lipodystrophy, or both (Kim et al., 2008; Austin et al., 2012; Garg et al., 2015; Schrauwen et al., 2015). The first mutation, c.G112T (p.E38X), is linked to lipodystrophy and leads to a complete loss of Cav1 protein expression (Kim et al., 2008). Two of the frameshift mutations, c.474delA (p.P158P fsX22), and c.473delC (p.P158H fsX22), generate a novel 21 amino acidlong C-terminus beyond amino acid position 158 associated with PAH (Austin et al., 2012). The third non-sense mutation, c.479_480delTT (p.F160X), introduces a premature stop codon that results in a truncated mutant protein lacking the last 19 amino acids of wild type Cav1 C-terminus. Interestingly, this mutation is associated with both $\mathrm{PAH}$ and congenital generalized lipodystrophy (Garg et al., 2015; Schrauwen et al., 2015).

How these mutant forms of Cav1 contribute to the development of PAH and/or congenital generalized lipodystrophy is not yet clear. However, one notable similarity shared by $\mathrm{P} 158 \mathrm{P} / \mathrm{H}$ and $\mathrm{F} 160 \mathrm{X}$ is that they occur in the distal C-terminus of Cav1. This domain of Cav1 is thought to be important for Cav1 homo-oligomerization, Golgi-plasma membrane trafficking, and DRM association (Song et al., 1997; Machleidt et al., 2000). Initial studies in patient skin fibroblasts show that the presence of either P158P fsX22 or the truncation mutant F160X lead to decreased Cav1 protein levels (Austin et al., 2012; Schrauwen et al., 2015). It is thus possible that at least some of the newly identified PAH-associated Cav1 mutants are targeted for degradation, and may also function as dominant negatives against wild type Cav1. Caveolae assembly appears to be at least partially preserved for the case of the F160X mutation (Garg et al., 2015), although pathway analysis indicates its expression impacts signaling pathways that are important adipose tissue homeostasis (Schrauwen et al., 2015). It will be interesting to determine whether caveolae form correctly for the P158P mutants and whether Cav1 follows a conventional trafficking and degradative pathway in these patients.

\section{REFERENCES}

Aboulaich, N., Vainonen, J. P., Stralfors, P., and Vener, A. V. (2004). Vectorial proteomics reveal targeting, phosphorylation and specific fragmentation of polymerase I and transcript release factor (PTRF) at the surface of caveolae in human adipocytes. Biochem. J. 383(Pt 2), 237-248. doi: 10.1042/BJ20040647

Ariotti, N., and Parton, R. G. (2013). SnapShot: caveolae, caveolins, and cavins. Cell 154, 704-704.e1. doi: 10.1016/j.cell.2013.07.009

Ariotti, N., Rae, J., Leneva, N., Ferguson, C., Loo, D., Okano, S., et al. (2015). Molecular characterization of caveolin-induced membrane curvature. J. Biol. Chem. 290, 24875-24890. doi: 10.1074/jbc.M115.644336

Austin, E. D., Ma, L., LeDuc, C., Berman Rosenzweig, E., Borczuk, A., Phillips, J. A. III, et al. (2012). Whole exome sequencing to identify a novel gene (caveolin1) associated with human pulmonary arterial hypertension. Circ. Cardiovasc. Genet. 5, 336-343. doi: 10.1161/CIRCGENETICS.111.961888

\section{CONCLUSION}

In summary, our understanding of how Cav1 assembles to form caveolae and is turned over outside of caveolae has increased tremendously over the past few years, yet is far from complete. A clear model of caveolae biogenesis has emerged, but additional work is needed to understand how disease-associated Cav1 mutants impact this process. Indeed, how wild type Cav1 itself is packed into caveolae is not yet entirely clear. How cells dispose of Cav1 in response to stress, and whether similar or different mechanisms are utilized to target various diseaseassociated mutants of Cav1 for degradation also remain to be more fully investigated. Some of these processes may be mimicked by overexpression of tagged forms of Cav1. Thus, further investigation of what may at first glance appear to be an artifact of tissue culture may ultimately reveal mechanisms that are of physiological and/or pathophysiological importance. Finally, it is important to recognize that a consensus model for how caveolae function does not yet exist (Cheng and Nichols, 2016). An important challenge for the future will be to better understand how abundance and structure of caveolae control the many functions currently ascribed to this intriguing class of membrane domains.

\section{AUTHOR CONTRIBUTIONS}

Drafted the manuscript or revising it critically for important intellectual content: BH, AT, CC, AK. Approved the final version of the manuscript to be published: $\mathrm{BH}, \mathrm{AT}, \mathrm{CC}, \mathrm{AK}$. Agree to be accountable for all aspects of the work: BH, AT, CC, AK.

\section{FUNDING}

Supported by NIH R01 HL111259 and R01 HL111259 01S1. The funding sources had no role in writing the report or the decision to submit the paper for publication.

\section{ACKNOWLEDGMENTS}

We thank Krishnan Raghunathan for constructive feedback on the manuscript.

Bakhshi, F. R., Mao, M., Shajahan, A. N., Piegeler, T., Chen, Z., Chernaya, O., et al. (2013). Nitrosation-dependent caveolin 1 phosphorylation, ubiquitination, and degradation and its association with idiopathic pulmonary arterial hypertension. Pulm. Circ. 3, 816-830. doi: 10.1086/674753

Burana, D., Yoshihara, H., Tanno, H., Yamamoto, A., Saeki, Y., Tanaka, K., et al. (2016). The Ankrd13 family of ubiquitin-interacting motifbearing proteins regulates valosin-containing Protein/p97 protein-mediated lysosomal trafficking of caveolin 1. J. Biol. Chem. 291, 6218-6231. doi: 10.1074/jbc.M115.710707

Cai, C., Weisleder, N., Ko, J. K., Komazaki, S., Sunada, Y., Nishi, M., et al. (2009). Membrane repair defects in muscular dystrophy are linked to altered interaction between MG53, caveolin-3, and dysferlin. J. Biol. Chem. 284, 15894-15902. doi: 10.1074/jbc.M109.009589

Cao, H., Alston, L., Ruschman, J., and Hegele, R. A. (2008). Heterozygous CAV1 frameshift mutations (MIM 601047) in patients with atypical 
partial lipodystrophy and hypertriglyceridemia. Lipids Health Dis. 7:3. doi: 10.1186/1476-511X-7-3

Carozzi, A. J., Roy, S., Morrow, I. C., Pol, A., Wyse, B., Clyde-Smith, J., et al. (2002). Inhibition of lipid raft-dependent signaling by a dystrophy-associated mutant of caveolin-3. J. Biol. Chem. 277, 17944-17949. doi: 10.1074/jbc.M1 10879200

Cha, S. H., Choi, Y. R., Heo, C. H., Kang, S. J., Joe, E. H., Jou, I., et al. (2015). Loss of parkin promotes lipid rafts-dependent endocytosis through accumulating caveolin-1: implications for Parkinson's disease. Mol. Neurodegener. 10:63. doi: 10.1186/s13024-015-0060-5

Cheng, J. P., and Nichols, B. J. (2016). Caveolae: one function or many? Trends Cell Biol. 26, 177-189. doi: 10.1016/j.tcb.2015.10.010

Cohen, A. W., Hnasko, R., Schubert, W., and Lisanti, M. P. (2004). Role of caveolae and caveolins in health and disease. Physiol. Rev. 84, 1341-1379. doi: 10.1152/physrev.00046.2003

Conrad, P. A., Smart, E. J., Ying, Y. S., Anderson, R. G., and Bloom, G. S. (1995). Caveolin cycles between plasma membrane caveolae and the Golgi complex by microtubule-dependent and microtubule-independent steps. J. Cell Biol. 131(6 Pt 1), 1421-1433.

Drab, M., Verkade, P., Elger, M., Kasper, M., Lohn, M., Lauterbach, B., et al. (2001). Loss of caveolae, vascular dysfunction, and pulmonary defects in caveolin-1 gene-disrupted mice. Science 293, 2449-2452. doi: 10.1152/physrev.00046.2003

Ferraldeschi, R., Latif, A., Clarke, R. B., Spence, K., Ashton, G., O'Sullivan, J., et al. (2012). Lack of caveolin-1 (P132L) somatic mutations in breast cancer. Breast Cancer Res. Treat. 132, 1185-1186. doi: 10.1007/s10549-012-1981-0

Forbes, A., Wadehra, M., Mareninov, S., Morales, S., Shimazaki, K., Gordon, L. K., et al. (2007). The tetraspan protein EMP2 regulates expression of caveolin-1. J. Biol. Chem. 282, 26542-26551. doi: 10.1074/jbc.M702117200

Gambin, Y., Ariotti, N., McMahon, K. A., Bastiani, M., Sierecki, E., Kovtun, O., et al. (2014). Single-molecule analysis reveals self assembly and nanoscale segregation of two distinct cavin subcomplexes on caveolae. Elife 3:e01434. doi: 10.7554/eLife.01434

Garcia-Mata, R., Gao, Y. S., and Sztul, E. (2002). Hassles with taking out the garbage: aggravating aggresomes. Traffic 3, 388-396. doi: 10.1034/j.16000854.2002.30602.x

Garg, A., Kircher, M., Del Campo, M., Amato, R. S., and Agarwal, A. K. (2015). Whole exome sequencing identifies de novo heterozygous CAV1 mutations associated with a novel neonatal onset lipodystrophy syndrome. Am. J. Med. Genet. A 167, 1796-1806. doi: 10.1002/ajmg.a.37115

Gervasio, O. L., Phillips, W. D., Cole, L., and Allen, D. G. (2011). Caveolae respond to cell stretch and contribute to stretch-induced signaling. J. Cell. Sci. $124(\mathrm{Pt}$ 21), 3581-3590. doi: $10.1242 /$ jcs. 084376

Han, B., Tiwari, A., and Kenworthy, A. K. (2015). Tagging strategies strongly affect the fate of overexpressed caveolin-1. Traffic 16, 417-438. doi: 10.1111/tra.12254

Hansen, C. G., Howard, G., and Nichols, B. J. (2011). Pacsin 2 is recruited to caveolae and functions in caveolar biogenesis. J. Cell Sci. 124(Pt 16), 2777-2785. doi: $10.1242 /$ jcs. 084319

Hansen, C. G., and Nichols, B. J. (2010). Exploring the caves: cavins, caveolins and caveolae. Trends Cell Biol. 20, 177-186. doi: 10.1016/j.tcb.2010.01.005

Hansen, C. G., Shvets, E., Howard, G., Riento, K., and Nichols, B. J. (2013). Deletion of cavin genes reveals tissue-specific mechanisms for morphogenesis of endothelial caveolae. Nat. Commun. 4, 1831. doi: 10.1038/ncomms2808

Hanson, C. A., Drake, K. R., Baird, M. A., Han, B., Kraft, L. J., Davidson, M. W., et al. (2013). Overexpression of caveolin-1 is sufficient to phenocopy the behavior of a disease-associated mutant. Traffic 14, 663-677. doi: $10.1111 /$ tra. 12066

Hayashi, K., Matsuda, S., Machida, K., Yamamoto, T., Fukuda, Y., Nimura, Y., et al. (2001). Invasion activating caveolin-1 mutation in human scirrhous breast cancers. Cancer Res. 61, 2361-2364.

Hayer, A., Stoeber, M., Bissig, C., and Helenius, A. (2010a). Biogenesis of caveolae: stepwise assembly of large caveolin and cavin complexes. Traffic 11, 361-382. doi: $10.1111 / j .1600-0854.2009 .01023 . x$

Hayer, A., Stoeber, M., Ritz, D., Engel, S., Meyer, H. H., and Helenius, A. (2010b). Caveolin-1 is ubiquitinated and targeted to intralumenal vesicles in endolysosomes for degradation. J. Cell Biol. 191, 615-629. doi: $10.1083 / \mathrm{jcb} .201003086$

Hill, M. M., Bastiani, M., Luetterforst, R., Kirkham, M., Kirkham, A., Nixon, S. J., et al. (2008). PTRF-Cavin, a conserved cytoplasmic protein required for caveola formation and function. Cell 132, 113-124. doi: 10.1016/j.cell.2007.11.042
Hyttinen, J. M., Amadio, M., Viiri, J., Pascale, A., Salminen, A., and Kaarniranta, K. (2014). Clearance of misfolded and aggregated proteins by aggrephagy and implications for aggregation diseases. Ageing Res. Rev. 18, 16-28. doi: 10.1016/j.arr.2014.07.002

Johnston, J. A., Ward, C. L., and Kopito, R. R. (1998). Aggresomes: a cellular response to misfolded proteins. J. Cell Biol. 143, 1883-1898.

Kim, C. A., Delepine, M., Boutet, E., El Mourabit, H., Le Lay, S., Meier, M., et al. (2008). Association of a homozygous nonsense caveolin-1 mutation with Berardinelli-Seip congenital lipodystrophy. J. Clin. Endocrinol. Metab. 93, 1129-1134. doi: 10.1210/jc.2007-1328

Kirchner, P., Bug, M., and Meyer, H. (2013). Ubiquitination of the N-terminal region of caveolin-1 regulates endosomal sorting by the VCP/p97 AAA-ATPase. J. Biol. Chem. 288, 7363-7372. doi: 10.1074/jbc.M112.429076

Kirkham, M., Nixon, S. J., Howes, M. T., Abi-Rached, L., Wakeham, D. E., HanzalBayer, M., et al. (2008). Evolutionary analysis and molecular dissection of caveola biogenesis. J. Cell Sci. 121(Pt 12), 2075-2086. doi: 10.1242/jcs.024588

Koike, S., Kodera, Y., Nakao, A., Iwata, H., and Yatabe, Y. (2010). Absence of the caveolin-1 P132L mutation in cancers of the breast and other organs. J. Mol. Diagn. 12, 712-717. doi: 10.2353/jmoldx.2010.090180

Kopito, R. R. (2000). Aggresomes, inclusion bodies and protein aggregation. Trends Cell Biol. 10, 524-530. doi: 10.1016/S0962-8924(00)01852-3

Kovtun, O., Tillu, V. A., Ariotti, N., Parton, R. G., and Collins, B. M. (2015). Cavin family proteins and the assembly of caveolae. J. Cell Sci. 128, 1269-1278. doi: $10.1242 /$ jcs. 167866

Kovtun, O., Tillu, V. A., Jung, W., Leneva, N., Ariotti, N., Chaudhary, N., et al. (2014). Structural insights into the organization of the cavin membrane coat complex. Dev. Cell 31, 405-419. doi: 10.1016/i.devcel.2014.10.002

Kraft, M. L. (2013). Plasma membrane organization and function: moving past lipid rafts. Mol. Biol. Cell 24, 2765-2768. doi: 10.1091/mbc.E13-03-0165

Kurzchalia, T. V., Dupree, P., Parton, R. G., Kellner, R., Virta, H., Lehnert, M., et al. (1992). VIP21, a $21-\mathrm{kD}$ membrane protein is an integral component of trans-Golgi-network-derived transport vesicles. J. Cell Biol. 118, 1003-1014.

Lacroix-Triki, M., Geyer, F. C., and Reis-Filho, J. S. (2010). Caveolin-1 P132L mutation in human cancers: 1 CAVeat to be voiced. J. Mol. Diagn. 12, 562-565. doi: 10.2353/jmoldx.2010.100093

LaRocca, T. J., Pathak, P., Chiantia, S., Toledo, A., Silvius, J. R., Benach, J. L., et al. (2013). Proving lipid rafts exist: membrane domains in the prokaryote Borrelia burgdorferi have the same properties as eukaryotic lipid rafts. PLoS Pathog. 9:e1003353. doi: 10.1371/journal.ppat.1003353

Le Lay, S., and Kurzchalia, T. V. (2005). Getting rid of caveolins: phenotypes of caveolin-deficient animals. Biochim. Biophys. Acta 1746, 322-333. doi: 10.1016/j.bbamcr.2005.06.001

Lee, H., Park, D. S., Razani, B., Russell, R. G., Pestell, R. G., and Lisanti, M. P. (2002). Caveolin-1 mutations (P132L and null) and the pathogenesis of breast cancer: caveolin-1 (P132L) behaves in a dominant-negative manner and caveolin-1 (-/-) null mice show mammary epithelial cell hyperplasia. Am. J. Pathol. 161, 1357-1369. doi: 10.1016/S0002-9440(10)64412-4

Liu, L., Brown, D., McKee, M., Lebrasseur, N. K., Yang, D., Albrecht, K. H., et al. (2008). Deletion of Cavin/PTRF causes global loss of caveolae, dyslipidemia, and glucose intolerance. Cell Metab. 8, 310-317. doi: 10.1016/j.cmet.2008.07.008

Ludwig, A., Howard, G., Mendoza-Topaz, C., Deerinck, T., Mackey, M., Sandin, S., et al. (2013). Molecular composition and ultrastructure of the caveolar coat complex. PLoS Biol. 11:e1001640. doi: 10.1371/journal.pbio.10 01640

Machleidt, T., Li, W. P., Liu, P., and Anderson, R. G. (2000). Multiple domains in caveolin-1 control its intracellular traffic. J. Cell Biol. 148, 17-28. doi: 10.1083/jcb.148.1.17

Martinez-Outschoorn, U. E., Sotgia, F., and Lisanti, M. P. (2015). Caveolae and signalling in cancer. Nat. Rev. Cancer 15, 225-237. doi: 10.1038/nrc3915

Mercier, I., Jasmin, J. F., Pavlides, S., Minetti, C., Flomenberg, N., Pestell, R. G., et al. (2009). Clinical and translational implications of the caveolin gene family: lessons from mouse models and human genetic disorders. Lab. Invest. 89, 614-623. doi: 10.1038/labinvest.2009.23

Monier, S., Dietzen, D. J., Hastings, W. R., Lublin, D. M., and Kurzchalia, T. V. (1996). Oligomerization of VIP21-caveolin in vitro is stabilized by long chain fatty acylation or cholesterol. FEBS Lett. 388, 143-149. 
Monier, S., Parton, R. G., Vogel, F., Behlke, J., Henske, A., and Kurzchalia, T. V. (1995). VIP21-caveolin, a membrane protein constituent of the caveolar coat, oligomerizes in vivo and in vitro. Mol. Biol. Cell 6, 911-927.

Mora, R., Bonilha, V. L., Marmorstein, A., Scherer, P. E., Brown, D., Lisanti, M. P., et al. (1999). Caveolin-2 localizes to the Golgi complex but redistributes to plasma membrane, caveolae, and rafts when co-expressed with caveolin-1. J. Biol. Chem. 274, 25708-25717.

Moren, B., Shah, C., Howes, M. T., Schieber, N. L., McMahon, H. T., Parton, R. G., et al. (2012). EHD2 regulates caveolar dynamics via ATP-driven targeting and oligomerization. Mol. Biol. Cell 23, 1316-1329. doi: 10.1091/mbc.E11-09-0787

Mougeolle, A., Poussard, S., Decossas, M., Lamaze, C., Lambert, O., and Dargelos, E. (2015). Oxidative stress induces caveolin 1 degradation and impairs caveolae functions in skeletal muscle cells. PLoS ONE 10:e0122654. doi: 10.1371/journal.pone. 0122654

Nomura, R., and Fujimoto, T. (1999). Tyrosine-phosphorylated caveolin-1: immunolocalization and molecular characterization. Mol. Biol. Cell 10, 975-986.

Owen, D. M., Magenau, A., Williamson, D., and Gaus, K. (2012). The lipid raft hypothesis revisited-new insights on raft composition and function from super-resolution fluorescence microscopy. Bioessays 34, 739-747. doi: 10.1002/bies.201200044

Palade, G. E. (1953). Fine structure of blood capillaries. J. Appl. Phys. 24, 1424-1436.

Parton, R. G., and del Pozo, M. A. (2013). Caveolae as plasma membrane sensors, protectors and organizers. Nat. Rev. Mol. Cell Biol. 14, 98-112. doi: 10.1038/nrm3512

Parton, R. G., and Simons, K. (2007). The multiple faces of caveolae. Nat. Rev. Mol. Cell Biol. 8, 185-194. doi: 10.1038/nrm2122

Patani, N., Lambros, M. B., Natrajan, R., Dedes, K. J., Geyer, F. C., Ward, E., et al. (2012). Non-existence of caveolin-1 gene mutations in human breast cancer. Breast Cancer Res. Treat. 131, 307-310. doi: 10.1007/s10549-011-1761-2

Pelkmans, L., Kartenbeck, J., and Helenius, A. (2001). Caveolar endocytosis of simian virus 40 reveals a new two-step vesicular-transport pathway to the ER. Nat. Cell Biol. 3, 473-483. doi: 10.1038/35074539

Pol, A., Martin, S., Fernandez, M. A., Ingelmo-Torres, M., Ferguson, C., Enrich, C., et al. (2005). Cholesterol and fatty acids regulate dynamic caveolin trafficking through the Golgi complex and between the cell surface and lipid bodies. Mol. Biol. Cell 16, 2091-2105. doi: 10.1091/mbc.E04-08-0737

Razani, B., Engelman, J. A., Wang, X. B., Schubert, W., Zhang, X. L., Marks, C. B., et al. (2001). Caveolin-1 null mice are viable but show evidence of hyperproliferative and vascular abnormalities. J. Biol. Chem. 276, 38121-38138. doi: 10.1074/jbc.M008340200

Razani, B., and Lisanti, M. P. (2001). Caveolin-deficient mice: insights into caveolar function human disease. J. Clin. Invest. 108, 1553-1561. doi: 10.1172/JCI200114611

Ren, X., Ostermeyer, A. G., Ramcharan, L. T., Zeng, Y., Lublin, D. M., and Brown, D. A. (2004). Conformational defects slow Golgi exit, block oligomerization, and reduce raft affinity of caveolin-1 mutant proteins. Mol. Biol. Cell 15, 4556-4567. doi: 10.1091/mbc.E04-06-0480

Rieth, M. D., Lee, J., and Glover, K. J. (2012). Probing the caveolin-1 P132L mutant: critical insights into its oligomeric behavior and structure. Biochemistry 51, 3911-3918. doi: 10.1021/bi3001853

Ritz, D., Vuk, M., Kirchner, P., Bug, M., Schutz, S., Hayer, A., et al. (2011). Endolysosomal sorting of ubiquitylated caveolin-1 is regulated by VCP and UBXD1 and impaired by VCP disease mutations. Nat. Cell Biol. 13, 1116-1123. doi: $10.1038 /$ ncb2301

Root, K. T., Plucinsky, S. M., and Glover, K. J. (2015). Recent progress in the topology, structure, and oligomerization of caveolin: a building block of caveolae. Curr. Top. Membr. 75, 305-336. doi: 10.1016/bs.ctm.2015.03.007
Rothberg, K. G., Heuser, J. E., Donzell, W. C., Ying, Y. S., Glenney, J. R., and Anderson, R. G. (1992). Caveolin, a protein component of caveolae membrane coats. Cell 68, 673-682.

Sargiacomo, M., Scherer, P. E., Tang, Z., Kubler, E., Song, K. S., Sanders, M. C., et al. (1995). Oligomeric structure of caveolin: implications for caveolae membrane organization. Proc. Natl. Acad. Sci. U.S.A. 92, 9407-9411.

Schrauwen, I., Szelinger, S., Siniard, A. L., Kurdoglu, A., Corneveaux, J. J., Malenica, I., et al. (2015). A frame-shift mutation in CAV1 is associated with a severe neonatal progeroid and lipodystrophy syndrome. PLoS ONE 10:e0131797. doi: 10.1371/journal.pone.0131797

Senju, Y., Itoh, Y., Takano, K., Hamada, S., and Suetsugu, S. (2011). Essential role of PACSIN2/syndapin-II in caveolae membrane sculpting. J. Cell Sci. 124(Pt 12), 2032-2040. doi: 10.1242/jcs.086264

Sevcsik, E., and Schutz, G. J. (2016). With or without rafts? Alternative views on cell membranes. Bioessays 38, 129-139. doi: 10.1002/bies.201500150

Shatz, M., Lustig, G., Reich, R., and Liscovitch, M. (2010). Caveolin-1 mutants P132L and Y14F are dominant negative regulators of invasion, migration and aggregation in H1299 lung cancer cells. Exp. Cell Res. 316, 1748-1762. doi: 10.1016/j.yexcr.2010.02.006

Shvets, E., Bitsikas, V., Howard, G., Hansen, C. G., and Nichols, B. J. (2015). Dynamic caveolae exclude bulk membrane proteins and are required for sorting of excess glycosphingolipids. Nat. Commun. 6:6867. doi: 10.1038/ncomms7867

Sinha, B., Koster, D., Ruez, R., Gonnord, P., Bastiani, M., Abankwa, D., et al. (2011). Cells respond to mechanical stress by rapid disassembly of caveolae. Cell 144, 402-413. doi: 10.1016/j.cell.2010.12.031

Song, K. S., Tang, Z. L., Li, S. W., and Lisanti, M. P. (1997). Mutational analysis of the properties of caveolin-1. A novel role for the C-terminal domain in mediating homo-typic caveolin-caveolin interactions. J. Biol. Chem. 272, 4398-4403.

Sotgia, F., Woodman, S. E., Bonuccelli, G., Capozza, F., Minetti, C., Scherer, P. E., et al. (2003). Phenotypic behavior of caveolin-3 R26Q, a mutant associated with hyperCKemia, distal myopathy, and rippling muscle disease. Am. J. Physiol. Cell Physiol. 285, C1150-C1160. doi: 10.1152/ajpcell.00166.2003

Stoeber, M., Stoeck, I. K., Hanni, C., Bleck, C. K., Balistreri, G., and Helenius, A. (2012). Oligomers of the ATPase EHD2 confine caveolae to the plasma membrane through association with actin. EMBO J. 31, 2350-2364. doi: 10.1038/emboj. 2012.98

Walser, P. J., Ariotti, N., Howes, M., Ferguson, C., Webb, R., Schwudke, D., et al (2012). Constitutive formation of caveolae in a bacterium. Cell 150, 752-763. doi: 10.1016/j.cell.2012.06.042

Wojcik, C., Schroeter, D., Wilk, S., Lamprecht, J., and Paweletz, N. (1996). Ubiquitin-mediated proteolysis centers in HeLa cells: indication from studies of an inhibitor of the chymotrypsin-like activity of the proteasome. Eur. J. Cell Biol. 71, 311-318.

Zimnicka, A. M., Husain, Y. S., Shajahan, A. N., Sverdlov, M., Chaga, O., Chen, Z., et al. (2016). Src-dependent phosphorylation of caveolin-1 Tyr14 promotes swelling and release of caveolae. Mol. Biol. Cell. doi: 10.1091/mbc.E15-11-0756. [Epub ahead of print].

Conflict of Interest Statement: The authors declare that the research was conducted in the absence of any commercial or financial relationships that could be construed as a potential conflict of interest.

Copyright (c) 2016 Han, Copeland, Tiwari and Kenworthy. This is an open-access article distributed under the terms of the Creative Commons Attribution License (CC $B Y)$. The use, distribution or reproduction in other forums is permitted, provided the original author(s) or licensor are credited and that the original publication in this journal is cited, in accordance with accepted academic practice. No use, distribution or reproduction is permitted which does not comply with these terms. 